\title{
Washback from the Bottom-Up: A Grounded Theory
}

\author{
Seyyed Ali Ostovar-Namaghi \\ Shahrood University of Technology, Iran \\ E-mail: saostovarnamaghi@yahoo.com
}

Received: 28-07-2013

doi:10.7575/aiac.ijalel.v.2n.6p.212
Accepted: 17-09-2013

Published: 01-11-2013

URL: http://dx.doi.org/10.7575/aiac.ijalel.v.2n.6p.212

\begin{abstract}
Theory-driven wash back studies inculcate the view that tests are the only causal factor determining what teachers and students do and as such ignore other local constraints. This data-driven study aims at filling in the gap in the wash back knowledge-base by conceptualizing teachers' perceptions of the university entrance exam (UEE) in Iran. In line with grounded theory, theoretically relevant concepts were sampled from qualitative interviews with experienced language teachers who were willing to share their views with the researcher. Iterative data collection and analysis revealed: (1) a set of local conditions that that make teachers shift away from language teaching towards preparing students for the UEE; (2) how the UEE deprives the nation from professional workforce by deprofessionalizing language teachers and producing a hose of communicatively incompetent high school graduates; and (3) data-driven suggestions for reform.
\end{abstract}

Keywords: wash back, grounded theory, deprofessionalization, local conditions, communicatively-incompetent learners

\section{Introduction}

Nation-wide tests can provide a nation with a skilled workforce or deprive it from this asset. The university entrance exam (UEE) in Iran has led the education system to prepare students for the test rather than for life. High school graduates in Iran have a high level of knowledge and a very low or a negligible level of skill because the UEE has shifted the stakeholders' attention away from learning and developing language skills towards passing this high-stake test. Nevertheless few data-driven studies have been undertaken to uncover why stakeholders have accepted the statusquo. This study aims at uncovering how stakeholders, the education system and the UEE work in synergy to create the status-quo. More specifically, it aims at describing teaching and learning activities, uncovering the local determinates of this mode of action, and predict the consequences of this mode of action for language teachers and learners and society as a whole and provide the field with situated-knowledge of wash back which can shed some light on the knowledgebase of wash back which is wrongly supposed to be applicable across varied contexts.

\section{Review of Related Literature}

The investigation of the wash back effect of tests at the national level is the common point among lots of research studies (Ghorbani, 2008; Cheng, 1997, 2005; Cheng, Watanabe \& Curtis, 2004; and Watanabe, 2004). According to Ghorbani (2008), the centralized control of curriculum and assessment in Iran is assumed to have led to teaching towards the high-stakes university entrance exam which affects the future career and lives of pre-university and senior high school students. According to Cheng (2005) examinations have been used as a means of control and as a way to counter nepotism and favoritism in the allocation of scarce opportunities. They have also been used to encourage the development of talent, upgrade the school performance, and select for education and employment for many years. As pointed out by Chapman and Snyder (2000, p. 458), high-stakes tests will have a greater influence on teaching and learning if their "primary use is to ration future opportunity as the basis for determining admission to the next layer of education or to employment opportunities".

Literature reveals a narrow and a broad definition of wash back: the narrower definition of wash back focuses on the effects that a test has on teaching and learning; the wider or more holistic view of wash back (also defined as test impact) looks beyond the classroom to the educational systems and society at large. All in all, tests can have a "significant impact not only on individuals but also on practices and policies - in the classroom, the school, the educational system and in society as a whole" (Wall, 2005). Although this definition may imply that there is a consensus in defining the scope of wash back, quite different terms have been used to conceptualize this concept:

- Test impact to describe the effects of tests on teaching and learning, the educational system, and the various stake holders in the education process (Bachman \& Palmer, 1996; Wall, 1997; McNamara, 2004).

- Systemic validity to describe the effects the introduction of a test has on instruction (Fredericksen \& Collins, 1989).

- Consequential validity to describe the impacts of testing on test takers and teachers, the examination of results by decision makers, and the potential misuse, abuse, and unintended usage of tests (Messick, 1996) 
- Measurement-driven instruction to describe the use of an external device for creating impact the educational process (Shohamy, Donitsa-Schmidt, \& Ferman, 1996)

- Wash back to the learners to indicate the effects of test on students ( Bailey,1999).

- Wash back to the programme to indicate effects of test on teachers, administrators, curriculum developers, counselors ( Bailey,1999).

Tests can have a positive or negative impact on both individuals and language teaching programs. Some scholars have specified its positive effects:

- Good tests can be utilized and designed as beneficial teaching-learning activities so as to encourage a positive teaching-learning process (Pearson, 1988).

- A creative and innovative test can quite advantageously result in a syllabus alteration or a new syllabus (Davis, 1985).

- Decision makers use the authority power of high-stakes testing to achieve the goals of teaching and learning, such as the introduction of new textbooks and new curricula (Cheng; 2005).

On the other hand, others have specified the negative consequences of tests:

- Tests can lead to the narrowing of content in the curriculum; what students have learned is test language, instead of total phases of understanding (Shohamy, 1992).

- Teachers tend to ignore subjects and activities that are not directly related to passing the exam, and tests accordingly alter the curriculum in a negative way (Vernon, 1956).

- Tests may fail to create a correspondence between the learning principles and/or the course objectives to which they should be related (Cheng, 2005).

- Testing programmes substantially reduce the time available for instruction, narrow curricular offerings and modes of instruction, and potentially reduce the capacities of teachers to teach content and to use methods and materials that are incompatible with standardized testing formats" (Smith, 1991).

Wash back from high-stakes tests was given special attention since research confirmed these tests' deleterious effects on stakeholders (Shohamy, Donitsa-Schmidt \& Ferman, 1996). Many studies on the extent and types of wash back from high-stakes tests have considered wash back for the participants and processes concurrently because of the interdependence of teachers (participants) using certain preparation processes (changing course content; using certain materials) due to wash back's effects (Bailey, 1999; Spratt, 2005).

Teachers' pervasiveness as subjects of wash back research arose because of their control in classrooms, coupled with the facts they are easier to communicate with and have less imminent stress on their lives as a result of high-stakes tests (Shohamy, Donitsa-Schmidt \& Ferman, 1996; Spratt, 2005). Language teachers play pivotal roles in effecting wash back because of their pedagogical and ethical decisions about class content and methodology for high-stakes testpreparation courses as opposed to other courses (e.g. Hamp-Lyons, 1997; Read \& Hayes, 2004).Nevertheless, other wash back causes were discovered alongside teachers' methods - for example, parents, textbooks, the class's focus, financial stability, the perceived 'highness' of a test's stakes and the timing of the research with the test's imminence (Choi, 2008; Read \& Hayes, 2004; Shohamy, Donitsa-Schmidt \& Ferman, 1996).

Researchers found that modifications of high-stake tests do not always produce their intended effects (e.g. Cheng, 1999); they produce "indirect," "unpredictable" changes because : (1) they are mediated by other factors such as the teachers' education, individual learning styles of students, educational context, and the "selecting function" of highstakes tests (Qi, 2005); (2) teachers subjectively modifies the content of their test-preparation classes, but rarely their methodology (Wall, 2000).Hence wash back is "malleable" and necessitates further investigation of its complexities (Spratt, 2005, p. 23).

Since the 1990s, researchers have begun empirically accounting for language tests' wash back or impact. Taking the foregoing reservations into account, the empirical findings of wash back can be summarized as follows:

- English teachers in the upper grades in particular seem to be spending virtually all their time on examination techniques rather on the English fundamentals so badly needed (Madsen, 1976).

- The use of multiple-choice tests (MCT) would lead to a decline in the incidence teaching skills such as writing skills which could not be measured by MCT (Wesdorp, 1982).

- Almost all teachers spent a considerable amount of time preparing students for the SLC English exam. (Khaniya, 1990b, p. 238), but students' preparation for the SLC English exam did not contribute to their English proficiency (Khaniya, 1990b,).

- Teachers either specifically trained students for the IELTS test or combined EAP with IELTS preparation courses ((Adams, 1992).

- Language teachers play pivotal roles in effecting wash back because of their pedagogical and ethical decisions about class content and methodology for high-stakes test-preparation courses as opposed to other courses (Read \& Hayes, 2004).

- Modifications of high-stake tests do not always produce their intended effects because they are mediated by other factors (Qi, 2005). 
- No documented research is available on the psychometric properties of the tests in Iran since the officials are reluctant to allow independent researchers from outside the ministry to investigate the quality of the tests (Farhady \& Hedayati, 2009 ).

Although the foregoing studies present the practitioners with a lot of insights, they suffer from three shortcomings: (1) they consider teachers as active agents in the education process and ignore the fact that their own life is also negatively affected by high-stake test; (2) they inculcate the idea that tests are the only causal factor determining what teachers do; (3) they don't go beyond description and as such lack explanatory and predictive power because all of them describe what teachers do in the face of high stake-tests but none of them explains how other situational constrains exerted by stakeholders such as school principals, parents and students themselves shape teachers' action. To fill in this gap in the knowledge-base of wash back, this data-driven study aims at describing: (1) what teachers' do in the face of high-stake tests (action); (2) what determines teachers' action (conditions); and (3) the consequence of this mode of action on teachers and students (consequences). In short, it aims at developing a grounded theory of wash back that enjoys descriptive, explanatory and predictive adequacy.

\section{Research Method}

\subsection{Participants}

In line with grounded theory, this study sampled theoretically- relevant concepts from interview data. Thus it did not start with a predetermined statistical sample; rather it started with experienced language teachers who were willing to share their professional experience with the researcher. They were taken from public high schools in Kashmar, a major city in Central Khorasan Province. All the participants had received their Bachelors' degrees in TEFL. Following Patton (1990), intensity and maximum variation sampling was used to select a broad range of concepts and categories underpinning wash back. Having explained the purpose and rationale of the study and having sought participant consent, the researcher chose two male and five female English teachers, who had ten years of teaching experience.

\subsection{Data Collection and Analysis}

Since the study aimed at theorizing practitioners perspectives concerning wash back, we began the interview with a very general question to elicit information on how the university entrance exam (UEE) affected their practice. The collected data were analyzed and more analytic questions were devised to be asked in subsequent interviews. More specifically, initial data collection and analysis determined subsequent questions which helped us sample theoretically relevant concepts. Iterative data collection and analysis continued till theoretical saturation of concepts and categories was achieved, i.e. the researcher kept on collecting data until he "received only already known statements" (Seldén 2005, p. 124).

The interviews were all audio-recorded to be transcribed verbatim and meticulously analyzed soon after the interviews were done. The total time for interviewing each one of the teachers averaged 20 minutes, with a minimum of 10 minutes and a maximum of 25 minutes. All in all, 70 pages of transcribed interviews were analyzed to derive transient and final concepts and categories.

Having transcribed the interview data, the researcher analyzed them by the coding processes suggested by Strauss and Corbin (1998). In open coding, I initially examined, fractured and eventually collated interview transcripts to find transient concepts and categories. In axial coding, the researcher tried to elaborate the concepts and categories by specifying their dimensions and properties and then fining the interrelationships between concepts and categories. And finally selective coding helped the researcher find the core category that pulled the concepts and categories together into a unified whole. Final concepts and categories were verified through member-checking (Petrie, 2003). In line with the ethics of qualitative research, participants' real names were not identified in this study.

\section{Results}

This study aimed to explore how the UEE affects language teaching in public high schools of Iran. To this end, the researcher used grounded theory to collect and analyze qualitative data. Iterative data collection and analysis yielded a data-driven theory showing descriptive, explanatory and predictive validity. More specifically, it yielded three categories describing teachers' action, three categories explaining why teachers follow such a reductionist approach towards teaching, and two categories predicting the impact of the UEE on students and teachers.

\subsection{Description: Teaching in the Face of UEE}

What follows is a descriptive account of how the UEE shapes language teachers' performance by redefining their conception of good teaching. In short, the UEE has led to: (1) selective coverage in line with test samples; (2) teaching to the test; (3) teaching the UEE test samples.

\subsection{Selective Coverage in Line with Test Samples}

Language education in public high schools of Iran seems to have two main objectives: preparing students for the final exam and preparing them for the UEE. But the problem is that these two tests are not always the same in format and content. To solve this problem, language teachers try to cover the parts of the textbooks which frequently appear in the final exam as rapidly as possible. Having covered the weight-bearing parts of the book, teachers feel free to focus on the UEE, which is the second objective of the language course. Although students take the UEE test taking strategies as their main concern, final exams intervene; if they don't pass the final exam, they can't take the UEE. To this end, the 
teachers should cover the textbook selectively and as fast as possible. One of the participants explains how he finds which parts of the book are more important than the others:

To find out what is more important and what is less important, I take the previous final exam samples as the criterion. I try to analyze these samples, classify them and specify the frequency of occurrence of the specific aspects. More specifically, I try to find the match between the test content and textbook content. Having found the parts that are covered in the test, I cover them and ignore the other parts.

In addition to showing which aspects of the textbook are more frequently tested, previous final exam sample tests familiarize the students with test format and time limit. Another participant explains how he uses sample tests to testwise students:

First I teach selected parts of the textbook and then present the students with copies of previous sample tests. I tell the students to pay attention to the allocated time, test format and instructions carefully. Students do a sample test as homework and then I analyze the test in the classroom and present the students with model answer. Students learn from their mistakes by comparing their answers with model answers.

Some participants relate underachievement to students' low level of motivation. They think that exams motivate students to study. As such during the term, teachers give them several tests which are similar in form and content to the previous samples. Through repeated tests, not only can the students predict the test content, they also learn some test taking strategies. One of the participants explains:

When you teach, students do not learn. Only when you test, students are motivated to learn. Instead of teaching important parts, one should test important parts. Thus I try to teach those aspects of the textbook which are frequently tested and then I give them repeated tests on those aspects. When I first started teaching I wrongly supposed that learning depends on teaching. Thus most of my class time was devoted to teaching. Now based on my experience, I say that learning depends on testing. Thus I try to minimize teaching the selected parts of the textbook and maximize testing those parts.

\subsection{Teaching to the Test}

The UEE is a high-stake test and as such teachers devote a great deal of class time to prepare students for this test. To this end, popular teachers categorize the UEE tests and present them lesson by lesson in details. Since the UEE focuses on written skills, especially vocabulary, they focus on written skills at the cost of oral skill. One of the participants explains why he focuses more on skills that appear in the test and ignores the other skills:

In my classes, I focus more on reading skill, and devote no time to listening, writing or speaking because these skills are not evaluated in the UEE. I do not waste my class time on conversation or grammar; I use the time at my disposal to improve my students' reading skill and their vocabulary since these are covered in the UEE. Inexperienced teachers may wrongly suppose that they should cover the syllabus and as such teach oral skills as well. However, since this is not what students want, they lose their popularity among students.

An analysis of UEE clearly shows that this test disproportionately focus on vocabulary. Taking the content of the test and the students' needs into account, teaching in public high schools revolves around vocabulary. Considering the UEE, one of the participants states that it is the teachers' duty to improve their students' reading comprehension skill:

I advise that my students put more emphasis on vocabulary, because there are nearly 15 items on vocabulary, and just 5 grammar items. It is our duty to improve our students' reading and to help them to answer a maximum number of reading comprehension questions in the shortest time in the UEE. As our educational system dictates, we have to train our students to have a good reading skill; the reason is that when they enter the university, professors expect them to read science and technology in English.

When students take a language course in high schools of Iran, their main concern is entering the university rather than developing their language skills. Improving students' vocabulary knowledge prepares them for the UEE because their command of vocabulary enables them to understand texts more deeply and perform more effectively in the UEE. In elaborating this point, one of the participants explains:

As I review the annual UEE test, the clear point is that the proportion of vocabulary items is increasing compared to grammar items, following different strategies, I try to enlarge my students' vocabulary knowledge. The wider their vocabulary knowledge, the more items they can answer; furthermore, they can even do better in grammar and reading comprehension items.

Another participant believed that her classroom activities are in line with the UEE. Thus she puts more emphasis on reading, vocabulary and those grammatical structures which are more important for the UEE. In this regard, she states:

It is the UEE that tells me what to do and what not to do, what to cover and what not to cover. For example, there are a few grammar items in the UEE, so I devote the least class time to teaching grammar and I focus more on vocabulary, reading comprehension, and cloze passages because the UEE covers mainly these parts. I focus more on vocabulary and reading comprehension, because the UEE tests are more oriented towards vocabulary and reading comprehension and less towards grammar.

Participants' comments clearly show how they are trapped in an examination preparation cycle and feel that the communicative and humanistic methodologies are luxuries they cannot afford (Prodromou, 1995). This is due to the 
fact that good teaching is responsive, i.e. teaching should respond to students' needs. Taking students' needs into account leads to mutual trust between language teachers and stakeholders; doing otherwise leads to mutual distrust.

\subsection{Teaching UEE Test Samples}

Education systems that aim at preparing students for future life ensure that teaching tasks resemble the target use tasks students may encounter in future. In our case, however, students' communicative efficiency in future is not the stakeholders' concern. Rather, the target task is nothing but a high-stake test. To ensure that teaching tasks and testing tasks are maximally similar, some teachers forget the textbook and replace it with previous samples of the UEE. The participants mentioned that they themselves and most of their students used commercial books which contained previous exams. Not only does this test-wises students to the form and content of the test, but also it improves their speed in doing test tasks in the national UEE speed test. There are even some UEE test preparation manuals that have analyzed previous samples and present the teacher and the students with classified tests. The following comments better illustrate why teachers shift their focus away from textbook towards commercially prepared test preparation manuals:

I give my students some sample tests in class. For example, for that part which is about conjunctions, I give them some examples and make them familiar with the UEE tests. With sample tests, students, really work better. I use "Kanoon Farhangi" test book. It has classified tests, lesson by lesson. I have to say that I present tests to my students each session lesson by lesson. Students suggest that I spend more time on test samples by ignoring the parts of textbook which are ignored in the UEE.

Another participant expresses similar concerns and explains how he uses test preparation manuals to test-wise the students and show them what is worth learning and what is not worth learning:

I cover "Mobtakeran" as a test-related book in my classes, and its tests are classified. The classifications presented by this manual helps students read their textbooks selectively by ignoring some parts and emphasizing other parts. Since with the time at my disposal, it's very difficult to cover the text book, I use the manual as a checklist guiding me through the book and helping me cover the parts that are covered in the test and ignore the parts which are ignored in the test.

Teachers ignore oral skills and related material in the textbook so as to have more time to cover test samples. This strategy leaves some room for presenting students with points and tips related to test taking. Participants believe that passing the UEE consists in knowing test taking strategies. Explaining the importance of test-taking strategies, one on the participants explains:

To prepare students for the UEE, we should familiarize our students with test taking strategies. Students who have high language proficiency are likely to perform badly in the UEE if we do not teach them how to take tests. I myself teach test taking strategies by presenting samples of UEE. I have to use the UEE tests and testrelated books in class to enrich my students test taking techniques, to show them the important parts of the book. I prefer not to do the textbook exercises; instead I teach previous samples of UEE.

Teachers ignore the textbook and focus on the UEE test samples and test taking strategies to reduce students' level of stress. In fact, students' level of stress depends on what teachers teach: when they teach the book, the stress level is high because students think the teacher is wasting their time. On the other hand, when they teach test samples, the level of stress is low because they think teaching activities prepares them for UEE. The following comments better explain the problem:

Students study for twelve years to take the UEE. The UEE is a matter of life and death. This test shapes their future. Thus language learning is very stressful. You can decrease students' stress by carefully selecting what to teach. When I teach test samples and test taking strategies students enjoy the class. Conversely, when I teach the book or something students consider as irrelevant to the UEE, classroom atmosphere is very tense. I use "Khate-Sefid" test preparation manual in my class because whenever I cover the tests in this book, students forget their worries about the UEE.

\subsection{Explanation: Determinants of Teaching}

The following section aims at explaining why teachers do what they do by presenting the social determinants of teaching. Iterative data collection and analysis uncovered that teachers focus on the UEE at the cost of language teaching because of: (1) the local definition of success; (2) stakeholders' intervention; (3) teachers' conception of teaching as a popularity contest.

\subsection{Local Definition of Success}

Throughout the system, the focus is on scoring well on the UEE rather than learning to communicate in English. That is, all stakeholders including the local boards of education, school principals, parents and students define success as scoring high in UEE. Thus students always worry about their performance in the UEE. To help the students overcome their worries, teachers should make sure that teaching activities improve students' performance in UEE. In their interviews teachers better explain how the local definition of success makes stakeholders intervenes in the teaching process. One of them explains: 
If you enable your students to communicate in English but you can't help them score high in the UEE, you will face various punitive measures. On the other hand, if your students perform well on the test, everybody respects you and the school principal and the students alike positively evaluate your performance.

English has no social function in Iran; therefore, being able to communicate in English is of secondary importance. On the other hand, the UEE is a high stake test since it determines students' future course of study and subsequently their future carrier. This makes stakeholders see students' performance on the test as the only yardstick of success. The school principal who is in charge of evaluating teaching performance says:

If you want to teach English, you should find a position in private language schools. Your duty is to respond to students' needs. Students don't come here to learn English; they come here to get ready for the test. You are successful if you prepare them for the test rather than improve their conversational skills.

Not only do stakeholders compare language teachers, they also compare high schools in terms of students' performance in the UEE. Merit schools and beacon schools admit teachers who have a good record in test preparation techniques. One teacher explains:

If you ignore test-taking techniques and do not have a good record in preparing students for the test, students and principals don't want you. Thus you lose your position in top high schools and for the subsequent years you should teach in schools that have no record in the UEE. When students, their parents and school principals define teaching as preparing students for the test, why should I lose my position by believing and acting otherwise?

\subsection{Stakeholders' Intervention}

It is the education system that hires the teachers and expects them to provide the students with their needs. Since parents' and students' main concern is students' performance in the UEE, the principal acts on their behalf and directs teaching activities. He is the most influential pressure since he evaluates teachers' performance and determines the rewards, increments and positions. In explaining the stakeholders' pressure, one of the participants states:

There are pressures, on the one hand, there is Educational Administration, and on the other, there are students and their parents, they expect teachers to guarantee their children's success and acceptance. If we do not make our students ready for the UEE, they will start to complain, their parents will complain too. It is so that after the announcement of the UEE results, the school and the Educational Administration will send an award for those teachers who have the highest acceptance percentage in the UEE.

Teachers can't ignore stakeholders' perspectives. Stakeholders' respect teachers' views only if they are in line with their definition of success. Teaching performance is acceptable if it accommodates' stakeholders' views. One participant explains:

You are a good teacher if you prepare students for the UEE. Parents prefer teachers who have a good record in the UEE test preparation techniques. Similarly, students favor teachers who prioritize test preparation. If teachers fail in this responsibility, they complain and the principals and parents intervene.

All the participants take students as the one of the main forces shaping teaching activities. Since performance in the UEE is the students' main concern, students force teachers to ignore teaching activities and materials that do not count in the UEE. The higher the students' expectations for being successful in the UEE, the higher the use of the UEE tests in class by teachers. The participants' comments better explain this scenario:

Since in the very first session students ask for good test books, their parents come over and want a list of good books for their students to be successful at the UEE. Thus teachers do their best not to fall short of students and parents' expectations. Teachers work under parent's surveillance: If their children do not work well in trial exams, they will come and inquire the reasons. They see us as the main factor for their children's success in the UEE.

A large number of teachers help students cope with examinations in order to preserve their reputation as good teachers (Khaniya,1990). Teachers do so because they are sure that they students compare them and their activities with other teachers. One of the participants states:

Since the UEE is one of the most important tests in our students' educational curriculum, students and their parents are very sensitive about that. Students compare teachers and their activities in class with each other. It is important for them that their teachers prepare them for the UEE. Students sometimes complain that for example: Mrs. Y is training students for the test, why not you? Mrs. Y is a very good teacher. She works on tests in her class. You know these days covering tests and test related books in class is what students and parents expect. Thus teachers should put this in their lesson plan.

The collected data from the interviews indicated a negative relationship between teachers' perceived external pressure in teaching and teachers' perceptions of the impact of the UEE on their activities. Teachers who felt more pressure to improve their students' test scores from different external sources, such as students, their principals, and educational administration, are more likely to be affected by the UEE.

\subsection{Teaching as a Popularity Contest}

In addition to external pressure from stakeholders, teachers are internally motivated to forget about language teaching and focus mainly on UEE test preparation because they see teaching as winning the popularity contest. Teachers who have a good record, teach in the best high schools and earn staggering sums of money by tutoring. On the other hand, 
teachers who are not favored by stakeholders, especially the students, have to worry about their position. Thus a great majority of teachers who have accepted the status-quo improve their students' knowledge of test-taking strategies to become popular. One participant explains:

I personally reject the UEE since it presents a limited view of proficiency by ignoring listening, speaking and pronunciation. Moreover, I think I have been professionally prepared to teach English rather than prepare students for a test which lacks in validity and reliability. But I ignore my language teaching skills because nobody cares about teachers' teaching skills and students' language abilities. Students are interested in test taking strategies. You are popular if you respond to their needs. Thus I deliberately ignore language teaching and focus exclusively on test taking techniques because this is want they want.

Teachers are evaluated by school principals and their views are shaped by the feedback they receive from the students. Since students favor teachers who focus on UEE tests and test taking strategies, teachers are compared in terms of students' performance in tests. To cover more tests and to make sure that the students understand the strategies, teachers use Persian as the language of instruction. One of the participants explains how using mother tongue as the language of instruction leads to positive evaluation of teachers who have very low language proficiency:

I personally believe when language teaching is reduced to nothing more than introducing a limited number of test taking strategies and evaluation of teaching performance is based on students' performance of a limiting and limited test, competent and incompetent teachers cannot be told apart and this leads to a situation of hostility and isolation among teachers. In our high schools teaching performance is shaped by students' likes and dislikes rather than teachers' teaching knowledge and skills. In such a situation, successful teachers are those who are ready to give up their teaching skills and provide the students with what they want rather than what they need and in doing so become more popular.

Participants believed that many of the currently popular teachers lose their popularity if evaluation of teaching performance focuses on evaluating teachers in terms of their skills and knowledge rather than a limited number of test taking strategies. One of the participants explains the reason as follows:

I know some language teachers who are very popular among learners despite their low level of knowledge and proficiency. You may think that I'm biased but I want you to personally check the professional records of some of these popular teachers, especially their GPA, their language proficiency and the university from which they graduated. If you take time and check their language proficiency, you will see that many of these popular teachers are not able even to communicate in English. Students never notice these teachers' incompetence because instruction is in Persian and there is no room for language teaching.

\subsection{Consequences}

Having explained why teachers do what they do, the researcher aims at predicting the consequences of the adopted mode of teaching and learning for teachers, learners and the whole nation. The results show that UEE deprives the nation of its professional workforce because: it moves teachers away from teaching towards preparing students for a limiting and limited test; and it moves students away from language learning towards test taking strategies and getting ready for a high stake national test. In a nutshell, the dire consequences of letting UEE overshadow teaching and learning can be conceptualized as: (1) de-professionalized teachers; and (2) communicatively incompetent students.

\subsection{De-professionalized Teachers}

The UEE seems to leave no room for teachers to use their own initiatives to improve their teaching skills. As it was previously mentioned, it is the students' likes and dislike that determine teachers' action. Since students' main concern is to pass the final exam, they favor teachers who are good at preparing students for the test, and this compels teachers to teach what is tested and ignore what is not tested. Since the test ignores oral skills, teachers are not willing to improve their knowledge and skills pertinent to teaching oral skills. Under the constraints imposed by stakeholders and the UEE, teachers can no longer exercise their professional autonomy to develop students' language skills, rather they are free to prepare students for the test. As Ostovar-Namaghi (2010) states, teaching to the test reduces teachers' roles to nothing more than an information transmitter rather than a decision maker who acts as the gate-keeper to his classroom. He can no longer decide "which curriculum and pedagogical strategies will be allowed to enter and to what degree" (Leuhamann, 2002, p.8). Acting as a cool implementer of stakeholders likes and dislikes, he finds no chance to use his professional knowledge and skills and lack of use leads to atrophy or de-professionalization. One of the participants better explains what happens to teachers' professional knowledge and skills:

Instead of following my own plan to prepare communicatively competent learners, I find myself following externally imposed plans. I am not free to apply what I have learned during the pre-service teacher education program. If I focus on developing learners' communication skills, I am marginalized. On the other hand, if I do what I am told to do, I am granted an award of advanced skills. The incentive scheme favors teachers who are famous for preparing students for the UEE rather than those who are famous for their language teaching skills.

Participants complain that their professional knowledge and skills are not recognized. What they have learned in preservice teacher education programs are of no use since the externally imposed syllabus determines what is worth teaching and learning and the externally imposed UEE determines what is worth testing. Under such conditions good practice is locally defined as covering the textbook and preparing the students for the test because success is measured in terms of student's performance in the UEE rather than their performance in actual language use. Being forced to 
follow a conformist approach, the teacher finds no chance to use his knowledge and skills to develop materials, teach them in a principled manner, and test teaching and learning efficiency through test development. One of the participants explains how the reductionist approach he is forced to follow leads to de-professionalization:

My teaching is limited to explaining grammar in Persian, translating reading comprehension texts into Persian, and preparing students for tests of predictable content and format. In this context I rarely find the opportunity to use English; therefore, I think I am unable to communicate in English. Since I teach nothing more than vocabulary, translation and grammar, I have lost my knowledge and skills in teaching listening, speaking writing and many other aspects.

Another participant explains that his popularity among students and other stakeholders is due to his skills in preparing students for the tests rather than his potential in preparing communicatively competent learners. He himself better explains his professional life:

Both students and schools like me because they think I am good at preparing students for the UEE but I think I have mastered the content of high school textbooks at the cost of my professional skills. This is what has happened to me. Three years ago the ministry of education administered a test to measure language teachers' knowledge. The results fell short of their expectations because teachers who have recently entered the profession outperformed popular and experienced teachers like me.

The UEE has led to a situation of distrust between language teachers and students. Since the UEE ignores oral skills teachers ignore these skills. Since language teachers rarely communicate in English, students wrongly suppose that teachers are not able to communicate in English. Thus students and private language schools rarely hire teachers who have a tenured position in schools. Instead they hire amateurs who have no TEFL background. One of the participants explains:

Oral proficiency is the main requirement for private language institutes. They hire teachers based on the results of an interview which aims at measuring the applicants' conversational skills. They may also take your teaching experience into account. However if you enjoy a good command of oral skills, they will hire you. Rarely one can see teachers with a pre-service language teacher education. This is because they do not trust school language teaches' oral skills.

\subsection{Communicatively-Incompetent Students}

There is a bifurcation in language education in Iran: schools teach English to prepare students for screening tests; and private language institutes teach conversational skills. Since parents are sure that school can't prepare their children to use English, those who can afford the tuition send their children private language institutes in the evening. One of the participants explains:

About 70 to 80 percent of my students take evening language courses at private institutes to develop their oral skills because the textbooks, final exams, and the UEE ignore these skills. Students don't like to learn English at schools but they think they have to. On the other hand, they really like to attend private institutes because they give them what they really like. To attract more students, they focus exclusively on oral skills and ignore written skills including grammar and vocabulary.

In theory, teachers should test what they teach. That is, language teachers should exercise their professional autonomy and develop materials and methods which are conducive to learners' language development and develop teacher-made achievement to ensure that the students have mastered the materials taught. In Iran, however, the process is reversed; it is the UEE that determines the materials and methods and as such teachers teach what is tested and ignore what is not tested. Since the test ignores oral skills, these skills are never covered. One participant explains:

My students are totally incompetent in listening and speaking. The reason is that the UEE and the high school textbooks totally ignore them. You can't teach vocabulary and expect your students to learn listening and speaking. The ever increasing number of private language institutes and their focus on listening and speaking is a response to students' weakness in oral skills. The UEE makes students learn what they don't really need and ignore what they are really interested in.

\section{Summary and Discussion}

Language teachers' action can be summarized as the rapid and selective coverage of the textbook, teaching to the test, and teaching the UEE test samples. This nationally-convergent approach can be related to the deterministic nature of the UEE. Analysis revealed that teachers teach the way they do because: (1) stakeholders measure success in terms of performance in the UEE; (2) stakeholders intervene if teachers do not teach in line with the UEE; and (3) teachers teach in line with the UEE to become popular and as such take teaching as a popularity contest. These determining conditions force teachers to shift their attention away from language teaching towards preparing students for the UEE. The natural consequence is that teachers lose their professional skills because the UEE leaves no room for the use of skills, and students never develop oral skills because the UEE makes students and teachers ignore these skills. In a nutshell, the UEE deprives the nation from skilled professionals by making teachers and learners take a reductionist view of language teaching and learning.

The results showed that students sacrifice their proficiency for achieving a certain score in the UEE since the test suffers from construct under-representation, i.e. it ignores many aspects of proficiency including oral skills. Along the same lines Farhady and Hedayati (2009, p. 133) contend that "due to the popularity of discrete point testing of language 
components (spelling, grammar, and vocabulary) at all grades, teachers were not able to implement their intended curriculum because students were concerned with their performance on the tests rather than their performance in actual communication in a foreign language." Similarly, Ostovar-Namaghi (2011) empirically evaluated Shiraz University Language Proficiency (SULPT) and found that the test suffers from construct under-representation and constructirrelevant variance. If these threats are minimized, the students' immediate-goal, i.e. to achieve a certain test score, materializes their long-term goal, i.e. language proficiency (Ostovar-Namaghi, 2011, p. 529).

To alleviate the inherent problems of the UEE, it is essential that the UEE test developers: (1) uncover the target use tasks, i.e. the real-life non-test tasks; (2) develop test tasks that maximally resemble target use tasks; and (3) direct language teachers and syllabus designers to develop teaching tasks that maximally resemble test tasks. Students sacrifice language proficiency for the UEE test score merely because the test tasks and target use tasks are different. If the test developers make sure that test tasks resemble target-use tasks, teachers, students and syllabus designers alike will focus on teaching tasks which resemble the test-and-target-use tasks. In this way achieving a high score in the UEE guarantees a high level of proficiency. If the UEE test tasks, the target-use tasks and teaching tasks overlap, then the students' long-term goal, i.e. language proficiency, and their short-term goal, i.e. their performance in the UEE, will overlap. Having ensured this overlap, the UEE test developers can resolve the problems of communicative incompetence and de-professionalization and induce an educational milieu which is conducive to growth for both teachers and learners.

\section{References}

Adams, B. (1992). Wash back - an investigation of the influence of the IELTS (International English Language Testing System) test on teaching as perceived by teachers. Unpublished master's thesis, Lancaster University, Lancaster.

Bachman, L. and A. Palmer. (1996). Language testing in practice. Oxford: Oxford University Press.

Bailey, K. (1999). Wash back in language testing. New Jersey, Princeton: Educational Testing Service.

Chapman D. W., \& Snyder, C. W. Jr. (2000). Can high stakes national testing improve instruction? Reexamining conventional wisdom. InternationalJournal of Educational Development, 20(6), 457-474.

Cheng, L. (1997). How does wash back influence teaching? Implications for Hong Kong. Language and Education 11 (1), 34-54.

Cheng, L. (1999). Changing assessment: wash back on teacher perceptions and actions. Teaching and Teacher Education, 15, 253-271.

Cheng, L. (2005). Changing language teaching through language testing: A wash back study. Cambridge: Cambridge University Press.

Cheng, L., Watanabe, Y. \&Curtis, A.(Eds.). (2004). Wash back in language testing: Research contexts and methods. London: Lawrence Erlbaum.

Davies, A. (1985). Follow my leader: Is that what language tests do? In Y. P. Lee, A.C.Y.Y. Fok, R. Lord, \&G. Ow, (Eds),New directions in language testing (pp.1-13). Oxford: Pergamon Institute of English.

Farhady, H., \& Hedayati, H. (2009). Language assessment policy in Iran. Annual Review of Applied Linguistics, 29, 132-141.

Frederiksen, J.K. \& Collins, A. (1989). A system approach to educational testing. Educational Researchers, 18 (6), 27 32.

Ghorbani, M. R. (2008). The washback effect of the university entrance examination on Iranian English teacherse curricular planning and instruction. The Iranian EFL Journal, (2), 60-87.

Read, J. \& Hayes, B. (2004). IELTS test preparation in New Zealand: Preparing students for the IELTS Academic Module. In L. Cheng and Y. J. Watanabe, with A. Curtis (eds.), Washback in language testing: Research contexts and methods (pp 97-111). Mahwah, NJ: Lawrence Erlbaum.

Hamp-Lyons, L. (1997). Wash back, impact and validity: Ethical concerns. Language Testing, 14(3), 295-303.

Khaniya, T.R. (1990b). Examinations as instrument for Educational change: Investigating the wash back effect of the Nepalese English exams. Unpublished doctoral dissertation, University of Edinburgh.

Madsen, H. (1976). New alternatives in EFL exams or how to avoid selling English short. English Language Teaching Journal, 30 (2), 135-144.

McNamara, D. S. (2004). SERT: Self-explanation reading training. Discourse Processes, 38, 1-30.

Messick, S. (1996). Validity and wash back in language testing. Language Testing, 13(4), 241-56.

Ostovar-Namaghi, S. A. (2011). A comparative study of test tasks and target use tasks. Theory and Practice in Language Studies, 1(5), 525-529.

Ostovar-Namaghi, S. A. (2010). A data-driven conceptualization of teacher evaluation. The Qualitative Report, 15(6), 1504-1522. 
Pearson, I. (1988). Tests as levers for change. In M. Chamberlain, Large-scale communicative language testing: a case study (pp. 35-46). Oxford: Pergamon Institute of English.

Prodromou, L. (1995). The Backwash Effect: From Testing to Teaching. Language Testing 1995, 49 (1): 13-25.

Qi, L. (2005). Stakeholders' conflicting aims undermine the washback function of a high-stakes test.Language Testing, 22, 142-173.

Shohamy, E. (1992). Beyond proficiency testing: A diagnostic feedback testing model for assessing foreign language learning. The Modern Language Journal. 76, 513-532.

Shohamy, E., Donitsa-Schmidt, S.\& Ferman, I. (1996). Test impact revisited: Wash back effect over time. Language Testing. 13 (3), 298-317.

Smith, M.L. (1991). Put to the test: The effects of external testing on teachers. Educational Researchers, 2(5), 8-11.

Spratt, M. (2005). Wash back and the classroom: The implications for teaching and learning of studies of wash back from exams. Language Teaching Research, 9, 5-29.

Vernon, P. E. (1956). The Measurement of Abilities (2nd ed.). London: University of London Press.

Wall, D. (2000). The impact of high-stakes testing on teaching and learning: Can this be predicted or controlled? System 28, 499-509.

Watanabe, Y. (2004). Methodology in wash back studies. In L. Cheng, Y. Watanabe \& A. Curtis (Eds.), Wash back in language testing: Research contexts and methods (pp. 19-36). Mahwah, N.J.: Lawrence Erlbaum.

Wesdorp, H. (1982) Backwash effects of language-testing in primary and secondary education. Journal of Applied Language Study 1 (1), 40-50. 